TEACHING TACTIC

\title{
Creating Digital Tours of Sacred Spaces
}

\author{
Benjamin Zeller \\ Lake Forrest College
}

\section{The context}

I incorporate visual and spatial analysis into many courses, but especially into a course I teach on sacred spaces in Chicago. My students, undergraduates at a national liberal arts college who generally take my courses as part of the general education curriculum, enter with little knowledge of religious spaces or traditions.

\section{The pedagogical purpose}

I teach students to analyze spaces on a macro level (e.g. architectural style) as well as micro (e.g. specific objects). To help students more deeply learn about these spaces, I charge them with creating educational digital tours wherein they need to highlight and explain different elements of the space. This requires students to engage symbolic, iconographic, liturgical, architectural, historical, and artistic features.

\section{Description of the strategy}

My students have little if any experience creating digital tours. I therefore have chosen relatively easy to use software and hardware (Panotour and Ricoh Theta cameras; Panotour has been discontinued, but Pano2VR makes a good replacement). I train them on the use of these tools in a single class session. Throughout the semester we study sacred space as a category, as well as studying specific examples in the classroom and in the field. During a three-hour class session in the last three weeks of the semester we visit a new sacred site, and I set students loose with cameras and notebooks to learn about the space. I help with the technology where I need to. Back on campus, students do more research and decide which elements of the space to feature. Students choose photos and write descriptions. If they are comfortable learning the software, they help put the tour together, otherwise I take their work and create a tour from the various features they have studied.

\section{Why it is effective}

The scholarship of teaching and learning has demonstrated that needing to teach about a subject helps students gain deeper and fuller understanding. This project takes that basic approach into the digital world. I happen to use $360^{\circ}$ hardware and software for this project, but it works in other media too. The important thing is charging students to independently learn about the elements of a sacred space and then collectively put it together. Students become experts on the space as they discuss what to highlight in our digital tour. They learn about a religious tradition as embodied in the practices that occur in its sacred spaces. They access the lived religious context as well as the specific historical and cultural contexts of a particular community of faith. 